Article

\title{
Effect of Cobalt on Microstructure and Wear Resistance of Ni-Based Alloy Coating Fabricated by Laser Cladding
}

\author{
Kaiming Wang ${ }^{1}$, Baohua Chang ${ }^{1, *}$ (D), Yongping Lei ${ }^{2}$, Hanguang $\mathrm{Fu}^{2, *}$ and Yinghua Lin ${ }^{3}$ \\ 1 State Key Laboratory of Tribology, Department of Mechanical Engineering, Tsinghua University, \\ Beijing 100084, China; kmwangbjut@163.com \\ 2 School of Materials Science and Engineering, Beijing University of Technology, Beijing 100124, China; \\ yplei@bjut.edu.cn \\ 3 Institute of Laser Advanced Manufacturing, Zhejiang University of Technology, Hangzhou 310014, China; \\ lyh351258@163.com \\ * $\quad$ Correspondence: bhchang@tsinghua.edu.cn (B.C.); hgfu@bjut.edu.cn (H.F.); Tel.: +86-10-6278-1182 (B.C.)
}

Received: 5 November 2017; Accepted: 4 December 2017; Published: 7 December 2017

\begin{abstract}
Ni-based alloy powders with different contents of cobalt (Co) have been deposited on a $42 \mathrm{CrMo}$ steel substrate surface using a fiber laser. The effects of Co content on the microstructure, composition, hardness, and wear properties of the claddings were studied by scanning electron microscopy (SEM), an electron probe microanalyzer (EPMA), X-ray diffraction (XRD), a hardness tester, and a wear tester. The results show that the phases in the cladding layers are mainly $\gamma$, $\mathrm{M}_{7}(\mathrm{C}, \mathrm{B})_{3}, \mathrm{M}_{23}(\mathrm{C}, \mathrm{B})_{6}$, and $\mathrm{M}_{2} \mathrm{~B}$. With the increase in Co content, the amounts of $\mathrm{M}_{7}(\mathrm{C}, \mathrm{B})_{3}, \mathrm{M}_{23}(\mathrm{C}, \mathrm{B})_{6}$, and $\mathrm{M}_{2} \mathrm{~B}$ gradually decrease, and the width of the eutectic structure in the cladding layer also gradually decreases. The microhardness decreases but the wear resistance of the cladding layer gradually improves with the increase of Co content. The wear resistance of the NiCo30 cladding layer is 3.6 times that of the NiCo00 cladding layer. With the increase of Co content, the wear mechanism of the cladding layer is changed from abrasive wear to adhesive wear.
\end{abstract}

Keywords: laser cladding; Ni-based alloy; Co content; microstructure; wear resistance

\section{Introduction}

Surface modification coatings are widely used in industrial production for surface strengthening and remanufacturing due to their high hardness and excellent wear resistance and superior corrosion resistance [1-4]. Rollers are key components in steel manufacturing equipment, which have a great influence on the steel production efficiency [5,6]. A surface modification coating on the roller surface can improve the roller cycle life and increase the efficiency in steel production $[7,8]$. Traditional surface modification technologies include surfacing welding and thermal spraying, which have the shortcomings of large deformation, serious cracks, uneven hardness distribution, and so on $[9,10]$.

Laser cladding is a new kind of surface modification technology, in which high-power lasers are used to melt alloy powders on the surface of substrates [11]. Compared with the traditional surface modification technologies, laser cladding has many advantages, such as a lower dilution rate, higher bonding strengths between the cladded layers and substrate, and less thermal deformation. Because the laser cladding process has rapid heating and cooling rates, it can create a fine microstructure during the solidification process [12-14]. With the fast development of laser cladding technology, more and more attention has been paid to the repairing area and has been developed rapidly [15-18]. Lewis et al. [19] used four different powders to improve the wear and rolling contact fatigue (RCF) life of rails by laser cladding. The results showed that the wear resistance of rails was improved and the RCF life was increased by laser 
cladding. Lin et al. [20] used the Taguchi analysis method to optimize the process parameters in laser cladding iron-based powder, and the optimized process parameters were used in the laser cladding of the surface of a turbine blade. The results showed that the tensile property was improved, which could be improved even further by tempering treatment. Some challenges that arise in laser cladding relate to the ability to produce high density material that is free of cracks and well bonded to the substrate deposits. Angelastro et al. [21] optimized some process parameters (translation speed, hatch spacing, etc.) with a mathematical model and experimental analysis for the realization of deposits that were almost fully dense, free of cracks, and well bonded to the substrate.

Ni-based alloy powders have good wettability, excellent wear resistance, a superior high temperature performance, and a moderate price, and are thus widely used in laser cladding [22-24]. Ma et al. [25] studied the effects of two kinds of light spots (wide beam spot and circular spot) on the microstructure and properties of the Ni60/WC cladding layer. The results showed that eutectic structures were different for the two kinds of light spots. The wear resistance of the cladding layer was remarkably improved by using the two laser spots. By adding some alloy components in the Ni-based alloy powder, the properties of the cladding layer can be further improved [26]. Zhang et al. [27] researched the influences of adding $\mathrm{CeO}_{2}$ into Ni60 alloy powder when laser cladding on the surface of the 6063Al substrate. The results showed that the addition of $\mathrm{CeO}_{2}$ could reduce the cracks and pores in the cladding layer. The distribution of elements in the cladding layer was more uniform and the dilution rate was decreased when the $\mathrm{CeO}_{2}$ was added. Ma et al. [28] investigated the modification effect of the Ti element on the Ni-based/ceramic composite cladding layer. It was found that a special mesh TiC structure was generated through the in-situ synthesis. The addition of Ti could significantly increase the nucleation rate of $\mathrm{CrB}$ ceramic phase and in turn refine the grains. As a result, the hardness and wear resistance of the cladding layer were improved.

The Co metal has an excellent high temperature performance and the Co powder has been widely studied in laser cladding. However, because pure Co powder is expensive, it is more often considered as an additive element in alloy powders to improve the performance of the cladding layer [29-31]. Gao et al. [32] researched the effect of the addition of Co on the microstructure and interfacial bonding properties when steels were laser cladded with iron-based powders. The results showed that the addition of Co into an iron-based alloy could increase the amount of dendritic structure in the cladding layer and improve the bonding strength between the cladding layer and substrate.

The study has been very limited so far on the effect of adding a certain amount of Co into Ni-based alloy powders during laser cladding. In the present study, the influence of Co on the microstructure, hardness, and wear resistance of an Ni-based alloy coating was studied for the laser cladding of the 42CrMo steel substrate. The obtained results were expected to provide technical guidance for the surface strengthening or repairing of rollers.

\section{Materials and Methods}

\subsection{Specimen Preparation}

Three kinds of Ni-based alloy powders (7.01 wt. \% Cr, 0.30 wt. \% C, 1.59 wt. \% B, 3.05 wt. \% Si, 3.24 wt. \% Fe, Bal. Ni) with different Co contents (0 wt. \%, 15 wt. \% and 30 wt. \%) were used in the present investigation; these alloys powder are referred to as $\mathrm{NiCo00,} \mathrm{NiCo15,} \mathrm{and} \mathrm{NiCo30,} \mathrm{respectively.}$ The substrate material used was 42CrMo steel (0.43 wt. \% C, 1.17 wt. \% Cr, 0.21 wt. \% Mo), and the dimensions of the substrate specimens were $150 \mathrm{~mm} \times 50 \mathrm{~mm} \times 10 \mathrm{~mm}$. The surface of the substrate was first burnished by sandpaper and then cleaned by acetone, and the alloy powders were dried at $100{ }^{\circ} \mathrm{C}$ for about $2 \mathrm{~h}$ before the laser cladding experiment. Laser cladding experiments were carried out on fiber laser processing systems, which mainly consisted of an IPG YLS-6000 fiber laser (IPG Photonics Corporation, Oxford, MA, USA), DPSF-2 powder feeding system (Beijing Aeronautical Manufacturing Technology Research Institute, Beijing, China) with a coaxial nozzle (HIGHYAG Corporation, Berlin, Germany), and a water cooling system. The output mode of the fiber laser was a continuous laser with a wave length of $1070 \mathrm{~nm}$. The maximum output power was $6 \mathrm{~kW}$, the dimensions of the laser beam 
were $5 \mathrm{~mm} \times 5 \mathrm{~mm}$ square spot, and the energy distribution was uniform. When a laser cladding process was completed, the specimens were cooled to room temperature in the air.

On the basis of previous experiments [33,34], the laser cladding process parameters were chosen as follows: the laser power, the scanning speed, and the feeding powder rate were $2000 \mathrm{~W}, 240 \mathrm{~mm} / \mathrm{min}$, and $15 \mathrm{~g} / \mathrm{min}$, respectively. The cladding layer fabricated was about $1.86 \mathrm{~mm}$ thick. In order to protect the molten pool from oxidation, high-purity argon shielding gas was supplied through the same coaxial nozzle for powder feeding, and the argon shielding gas flow was $15 \mathrm{~L} / \mathrm{min}$. Specimens were cut and polished along the cross-section of the cladding layer and were then etched with a solution of the aqua regia (the volume ratio of hydrochloric acid and nitric acid was 3:1). The etching was carried out at room temperature and the etching time was $50 \mathrm{~s}$. After the completion of etching, the residual etching solution was washed off by water, and the surfaces were dried with a blower.

\subsection{Microstructure Observation}

Microstructures of the cladding layers were characterized by an OLYMPUS BX51 optical metallographic microscope (OM) (OLYMPUS Corporation, Tokyo, Japan) and Quanta FEG650 scanning electron microscope (SEM) (FEI Company, Hillsboro, OR, USA). Element distributions were analyzed by the electron probe microanalyzer (EPMA) (SHIMADZU Corporation, Kyoto, Japan) and the energy disperse spectroscopy (EDS) (FEI Company, Hillsboro, OR, USA). Phase identification was carried out by X-ray diffraction (XRD) using a Shimadzu XRD-7000 X-ray diffractometer (SHIMADZU Corporation, Kyoto, Japan) with $\mathrm{Cu}-\mathrm{K}_{\alpha}$ radiation at $40 \mathrm{kV}$ and $200 \mathrm{~mA}$ as an X-ray source. A continuous scan mode was used. A scan at $0.02^{\circ}$ per step was performed in the $2 \theta$ range of $20-80^{\circ}$ to give a general overview of the diffraction peaks.

\subsection{Microhardness and Wear Resistance Tests}

The microhardness of the cladding layer was measured with a MICRO MET-5103 digital microhardness tester. The load was $5 \mathrm{~N}$ and the loading time was $10 \mathrm{~s}$. The microhardness of a cladding layer was the average of the three measurements. To evaluate the high temperature property of the cladding layer, the microhardness was also measured with the same method for the cladded layers after being tempered. In tempering heat treatment, the samples were first heated to $600{ }^{\circ} \mathrm{C}$, then held for $1 \mathrm{~h}$ in the furnace, and finally cooled in the air. Such tempering treatments were repeated four times for all samples, after which the oxides were removed from the surface of samples.

Wear resistance was evaluated with a M-200 wear test machine (type: MRH-3W, Jinan Sida Testing Technology Corporation, Jinan, China), of which the schematic diagram is shown in Figure 1. The detailed experimental parameters of the wear test are listed in Table 1 . The weight loss of the samples was measured by using a TG328B balance, which had a weighing range of $200 \mathrm{~g}$ and a precision of $0.1 \mathrm{mg}$ (Shanghai Liangping Corporation, Shanghai, China). The wear resistance of a cladding layer was defined as the ratio of wear time/weight loss, and its unit was $\mathrm{min} / \mathrm{mg}$. The greater the value, the better the wear resistance of a cladding layer. The morphology of the worn surfaces was observed with the Quanta FEG650 SEM.

Table 1. Experimental parameters of the wear test.

\begin{tabular}{cccccc}
\hline Wear Ring & $\begin{array}{c}\text { Ring Diameter } \\
(\mathbf{m m})\end{array}$ & $\begin{array}{c}\text { Rotating } \\
\text { Speed (r/min) }\end{array}$ & Load (N) & Time (min) & $\begin{array}{c}\text { Experiment } \\
\text { Temperature }\left({ }^{\circ} \mathbf{C}\right)\end{array}$ \\
\hline GCr15 Steel & 45 & 200 & 300 & 30 & 20 \\
\hline
\end{tabular}




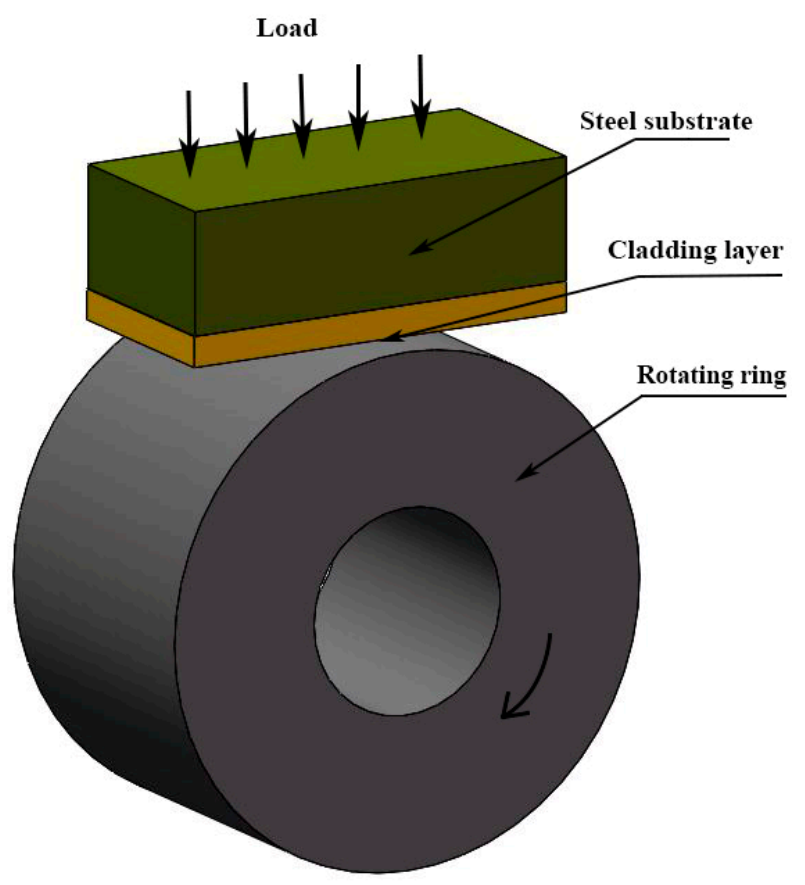

Figure 1. Schematic diagram of the wear tester.

\section{Results and Discussion}

\subsection{Phase and Microstructure}

Figure 2 shows the $\mathrm{X}$-ray diffraction spectrum of Ni-based cladding layers with different contents of Co. It can be found that the phases of the cladding layer include $\gamma, M_{7}(C, B)_{3}, M_{23}(C, B)_{6}$, and $M_{2} B$, where $\mathrm{M}$ is $\mathrm{Cr}$ and $\mathrm{Fe}$. The number and the intensity of peaks gradually decrease with the increase of Co content, and the amount of $\mathrm{M}_{7}(\mathrm{C}, \mathrm{B})_{3}, \mathrm{M}_{23}(\mathrm{C}, \mathrm{B})_{6}$, and $\mathrm{M}_{2} \mathrm{~B}$ decreases gradually. There is no elementary $C o$ phase in the cladding layers after the addition of $\mathrm{Co}$. This is because the atomic radius of $\mathrm{Co}$ and $\mathrm{Ni}$ is close, and Co is easily soluble in the Ni matrix.

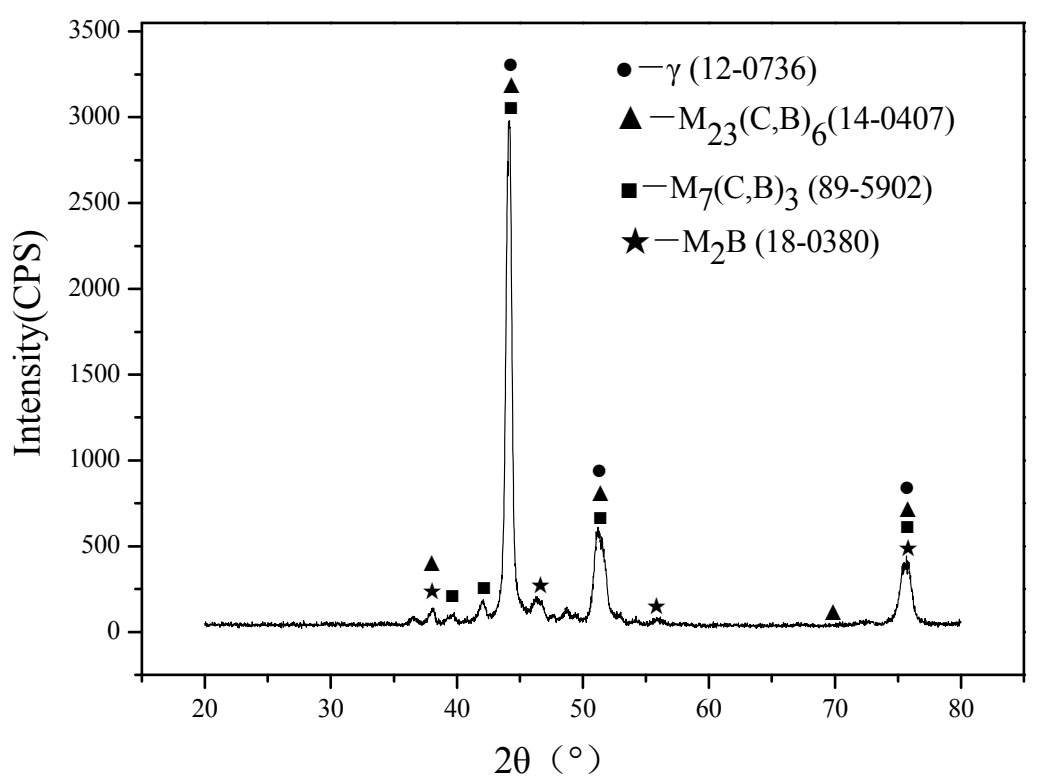

(a)

Figure 2. Cont. 


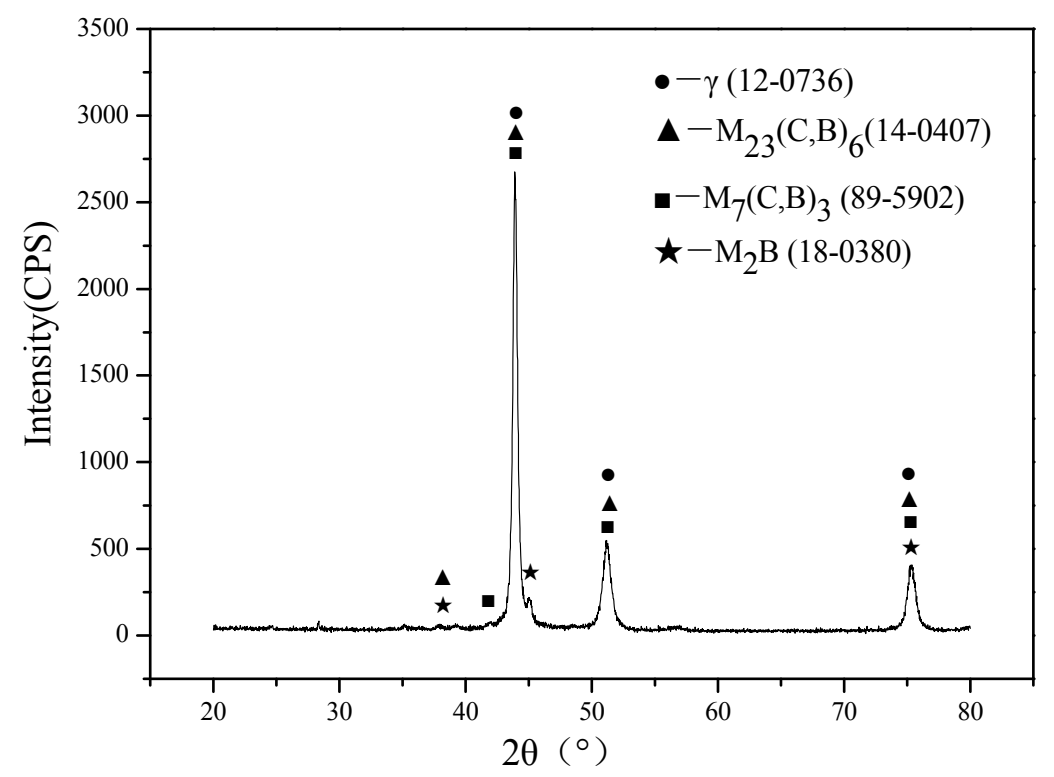

(b)

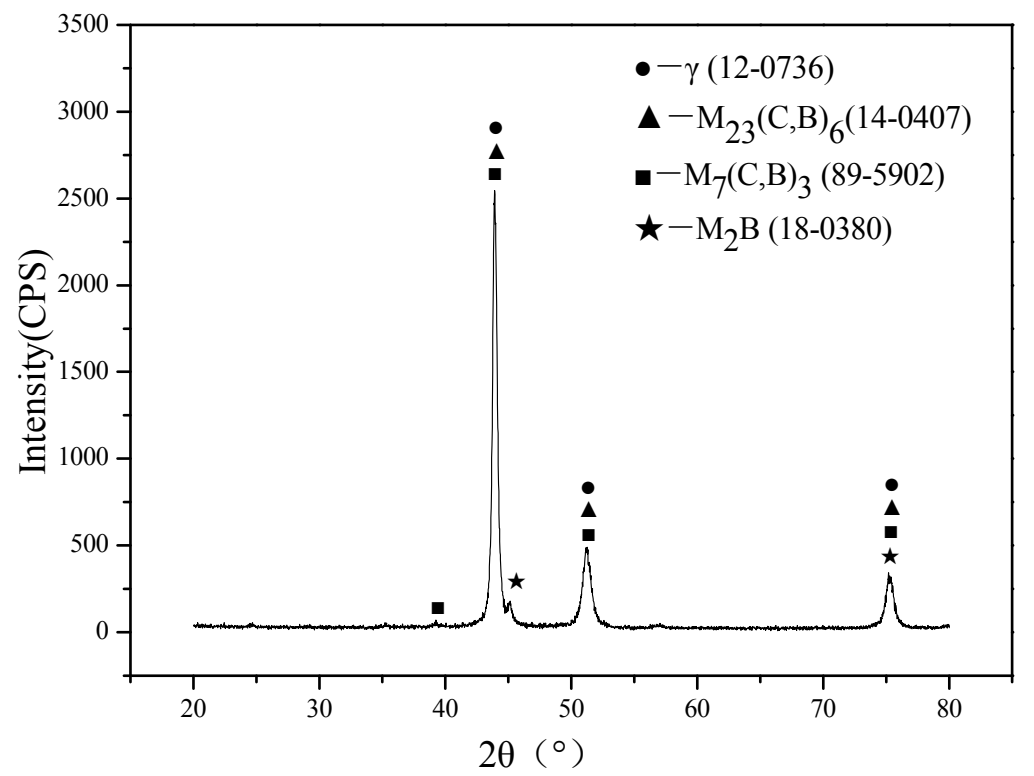

(c)

Figure 2. The XRD spectrum of the cladding layer: (a) NiCo00; (b) NiCo15; (c) NiCo30.

Figure 3 presents the optical micrographs of the cladding layers with different Co contents. From Figure 3a,c, light lines can be seen between the substrates and the cladding layers; these light lines are fusion lines indicating that good metallurgical bonding has been achieved between the substrates and the cladding layers. From Figure 3, it can be seen that the microstructure of the cladding layer is transformed from columnar dendrites to equiaxed grains with the increase of the distance from the fusion lines. The microstructure of the cladding layer is mainly determined by the ratio $(G / R)$ of temperature gradient $(G)$ and solidification rate $(R)$ during solidification. When the value of $G / R$ is large, the microstructure usually grows as columnar dendrites. When the value of $G / R$ is small, the microstructure is developed as equiaxed grains [35]. The temperature gradient $(\mathrm{G})$ decreases, while the solidification rate $(R)$ increases from the bottom to the top surface of the molten pool $[1,36]$. This means that the $G / R$ decreases from the bottom to the top surface of the molten pool during solidification. Therefore, the microstructure of the cladding layer transforms from columnar dendrites to equiaxed grains with the increase of the distance from the fusion lines. 

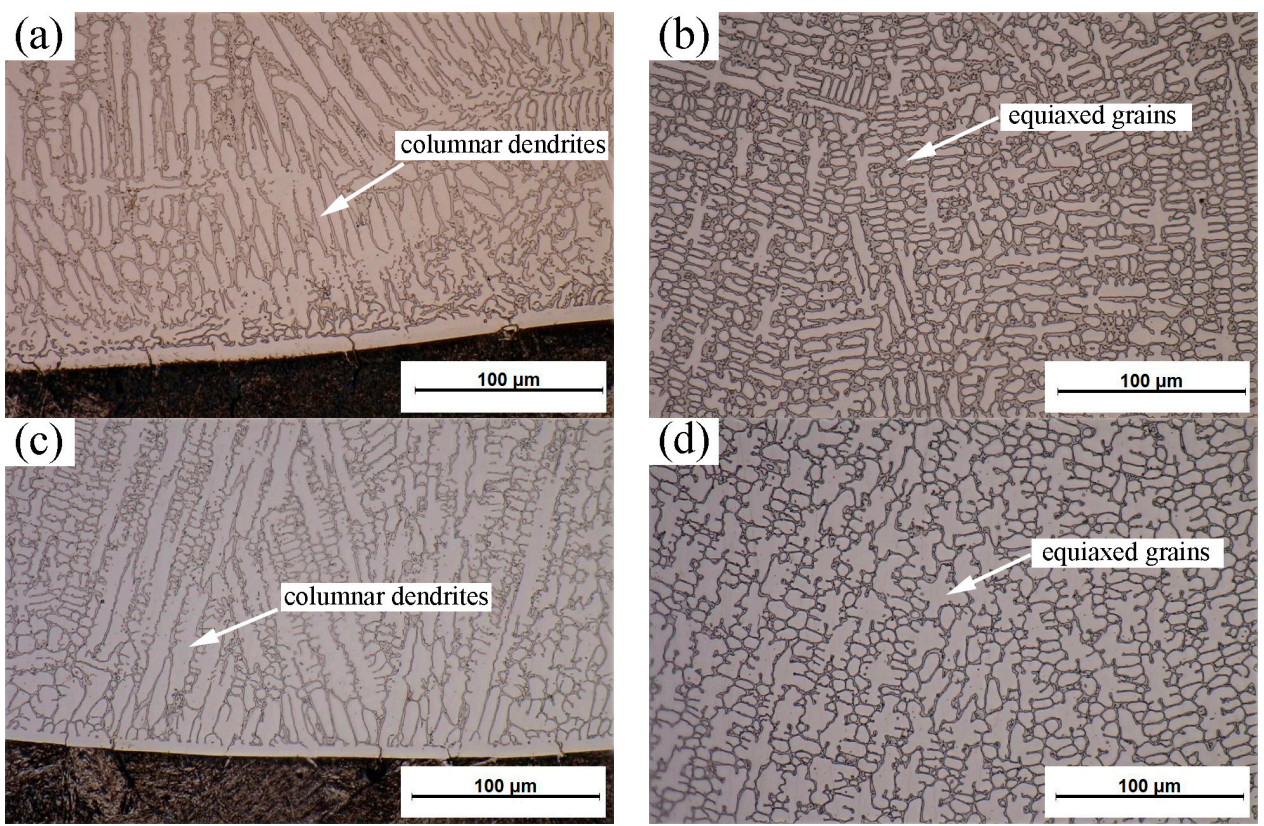

Figure 3. Optical micrographs of the cladding layer: (a) The bottom of NiCo00; (b) The middle of NiCo00; (c) The bottom of NiCo30; (d) The middle of NiCo30.

SEM analysis results of the middle of the cladding layers with different Co contents are presented in Figure 4. It is shown that the cladding layers are mainly composed of dark dendrite and bright eutectic structures. During the solidification process, the dendrites first precipitate from the liquid phase, and finally the eutectic structures are formed at grain boundaries. Chemical compositions of the eutectic structure (point 1 ) and dendrite (point 2 ) in Figure 4c were analyzed by EPMA point scanning, and the results are listed in Table 2. The contents of $\mathrm{Cr}$ and $\mathrm{C}$ in the eutectic structure (point 1) are notably higher than those in dendrites, which indicates that $\mathrm{Cr}$ and $\mathrm{C}$ elements are mainly precipitated at grain boundaries. Combined with the $\mathrm{XRD}$ results shown in Figure 2, the eutectic structures are mainly composed of $\mathrm{M}_{7}(\mathrm{C}, \mathrm{B})_{3}, \mathrm{M}_{23}(\mathrm{C}, \mathrm{B})_{6}$, and $\mathrm{M}_{2} \mathrm{~B}$. The dendrite (point 2 ) is mainly composed of $\mathrm{Ni}$ elements plus a certain amount of $\mathrm{Cr}$ and $\mathrm{Co}$, which indicates that the dendrite mainly consists of $\gamma$ matrix phase. With the increase of Co content, the width of the eutectic structures in the cladding layers decreases gradually. This is because Co can increase the solubility of $\mathrm{Cr}$ and $\mathrm{C}$ in the $\gamma$ matrix, which decreases the width of the eutectic [37]. This is consistent with the XRD results where the amount of $\mathrm{M}_{7}(\mathrm{C}, \mathrm{B})_{3}, \mathrm{M}_{23}(\mathrm{C}, \mathrm{B})_{6}$, and $\mathrm{M}_{2} \mathrm{~B}$ decreases with the increase of the Co content.
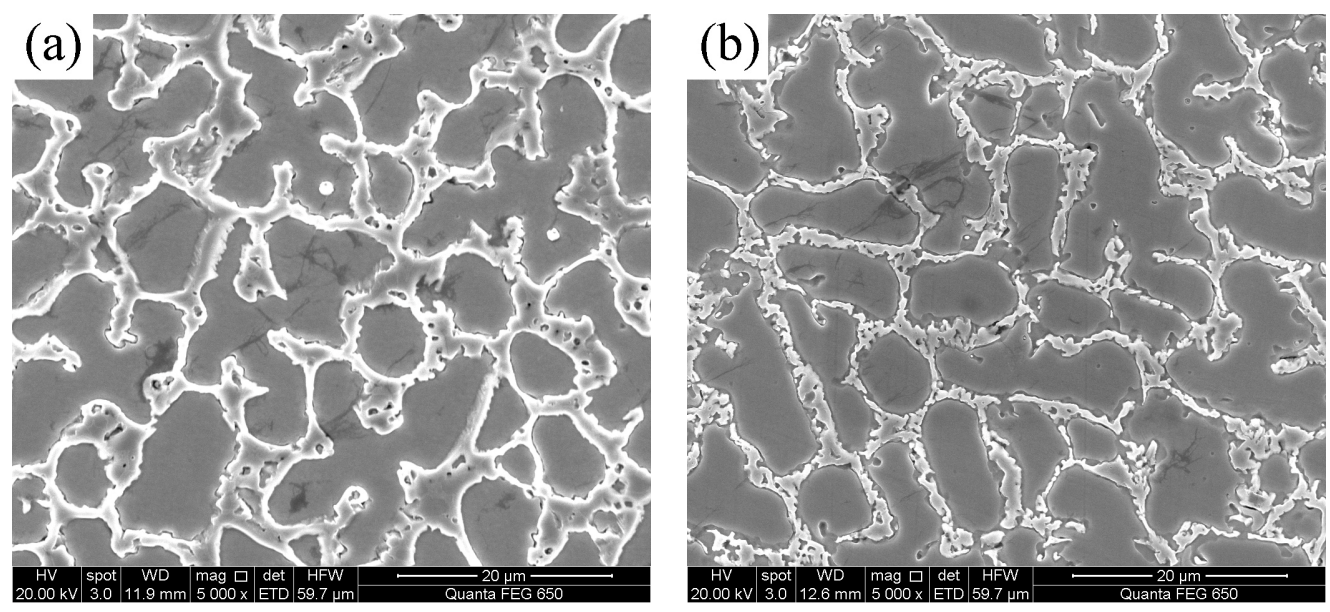

Figure 4. Cont. 


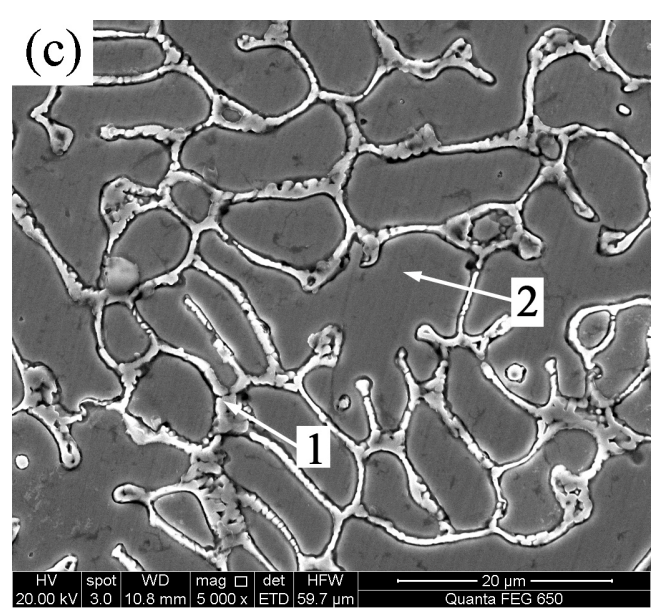

Figure 4. The SEM of Ni-based cladding with different Co contents: (a) NiCo00; (b) NiCo15; (c) NiCo30 (point 1-eutectic structure, point 2-dendrite).

Table 2. The EPMA results of the point scan (wt. \%).

\begin{tabular}{cccccccc}
\hline \multirow{2}{*}{ Point } & \multicolumn{7}{c}{ Chemical Composition (wt. \%) } \\
\cline { 2 - 8 } & Cr & C & Co & B & Si & Fe & Ni \\
\hline Point 1 & 29.955 & 6.512 & 23.583 & 0.930 & 0.579 & 0.979 & 36.564 \\
Point 2 & 15.329 & 0.922 & 34.026 & 0.471 & 0.556 & 1.659 & 47.847 \\
\hline
\end{tabular}

\subsection{Microhardness}

Figure 5 shows the microhardness of the Ni-based alloy laser claddings with different Co contents. The microhardness of the NiCo00 cladding layer is $379.1 \mathrm{HV}$ and the microhardness of the NiCo30 cladding layer is $252.8 \mathrm{HV}$. With the increase of the Co content in the Ni-based alloy cladding layer, the microhardness of the cladding layer is decreased. The main reason for this is that the addition of the Co element improves the solubility of $\mathrm{Cr}$ and $\mathrm{C}$ in the $\gamma$ phase, which results in a decrease in the amount of the hard phase $\mathrm{M}_{7}(\mathrm{C}, \mathrm{B})_{3}, \mathrm{M}_{23}(\mathrm{C}, \mathrm{B})_{6}$, and $\mathrm{M}_{2} \mathrm{~B}$ in the cladding layer. So, the microhardness of the cladding layer decreases with the increase of $\mathrm{Co}$ content. The above results are consistent with the results reported by $\mathrm{Li}$ et al. [38]. Figure 5 also indicates that the microhardness of the NiCo00 cladding layer decreases most notably after a high temperature tempering experiment. In contrast, the microhardness of the NiCo30 cladding layer increases slightly after high temperature tempering, which indicates that the addition of $\mathrm{Co}$ in the Ni-based alloy can improve the high temperature property of the cladding layer. 


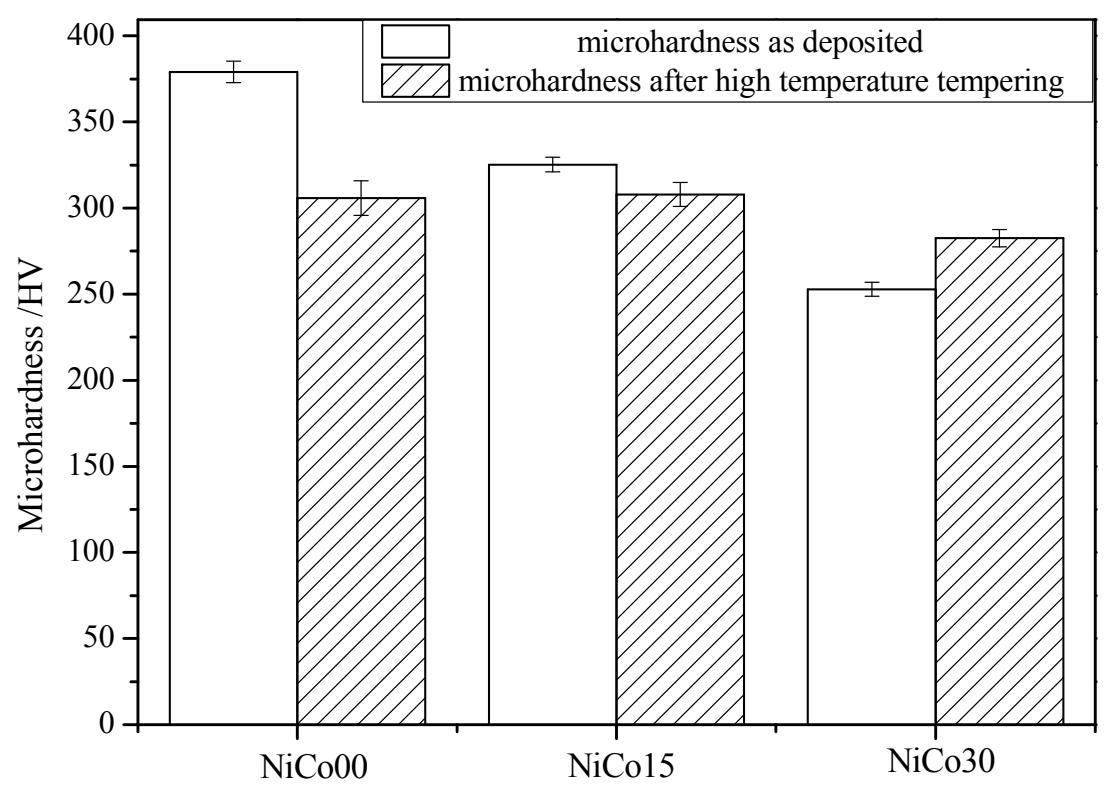

Figure 5. Microhardness of the cladding layers with different Co contents.

\subsection{Wear Resistance}

Weight loss and wear resistance of Ni-based cladding layers with different Co contents are shown in Figure 6. The weight loss of the cladding layer decreases gradually with the increase of the Co content. The wear resistance of the NiCo30 cladding layer is the best, which is about 3.6 times that of the NiCo00 cladding layer. Obviously, the addition of Co in the Ni-based alloy can significantly improve the wear resistance of the cladding layer.

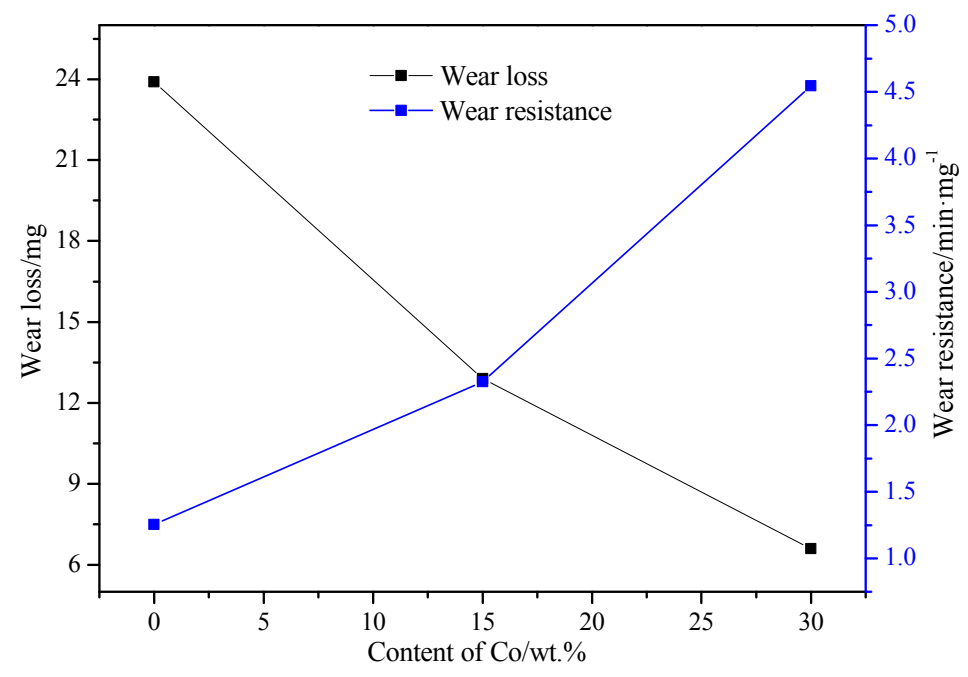

Figure 6. Weight loss and wear resistance of the cladding layers.

Worn morphologies of cladding layers with different Co contents were observed using SEM, as shown in Figure 7, through which the wear mechanism could be analyzed. It can be seen from Figure 7a that deep furrows appear in the worn surface of the cladding layer, which is characteristic of abrasive wear. When the Co element is added to the Ni-based alloy cladding layer, the furrows on the worn surface become significantly shallower (as shown in Figure $7 \mathrm{~b}, \mathrm{c}$ ). In addition, debris can be found on the worn surfaces, and the amount of debris increases significantly with the increase of Co content, suggesting that the main wear mechanism of the cladding layer has changed from abrasive wear to adhesive wear. 

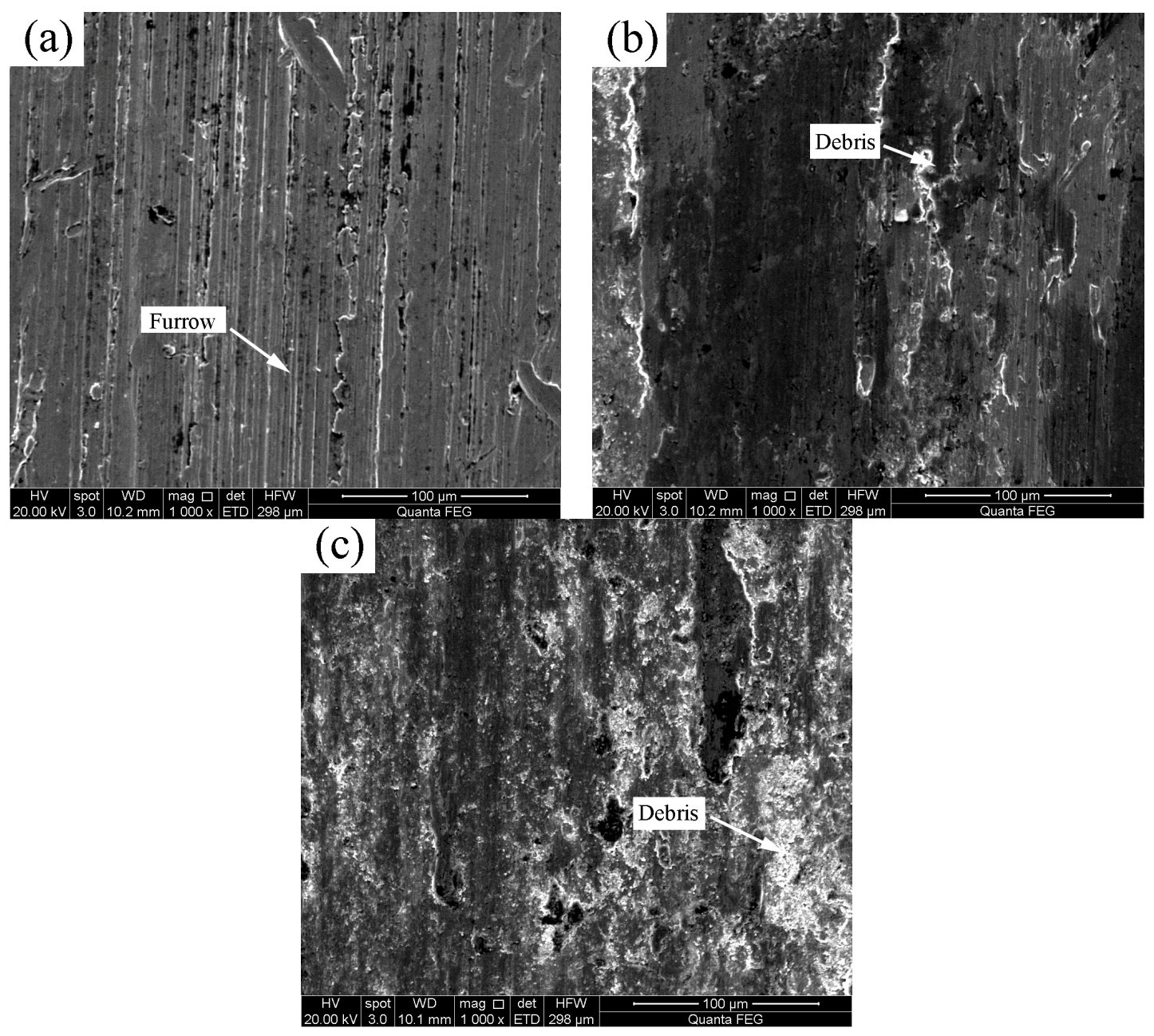

Figure 7. Morphologies of worn surfaces of Ni-based claddings with different Co contents: (a) NiCo00; (b) NiCo15; (c) NiCo30.

Worn morphology of the NiCo30 cladding layer under high magnification is observed, as shown in Figure 8a. There is much debris on the surface of the cladding layer. EDS (energy disperse spectroscopy) analysis of the debris (Figure 8b) finds that the debris contains a large amount of $\mathrm{O}$, which indicates that oxidation occurs during the wear process. This is because the frictional heating increases the temperature of the wear surface during the wear process. According to existing research results [39], the transient temperature of real contact areas of the wear process may be higher than $800{ }^{\circ} \mathrm{C}$. This can promote the formation of oxide on the surface of the cladding layer. The oxide can avoid direct contact between the cladding layer and the rotating ring and reduce the volume loss of the cladding layer and improve the wear resistance of the cladding layers. Chakraborty and Fernández et al. [40,41] also got a similar result, showing that the formation of oxide can increase the wear resistance of the cladding layer.

From the wear tests, it is found that the wear resistance of the Ni-based cladding layer can be improved by adding a certain amount of Co element. There are three possible reasons for this. First, the Co can be dissolved in the $\gamma$ matrix, which can result in solid solution strengthening effects in the matrix and improve the wear resistance of the cladding layer. Second, friction heat is generated during the wear process, which will increase the temperature of the surface of laser cladding. The addition of Co can improve the high temperature mechanical properties of the cladding layer (as shown by the microhardness test results of deposits after being tempered), and are therefore beneficial to the wear resistance of the cladding layer. Third, the main wear mechanism of the cladding layer changes from abrasive wear to adhesive wear with the increase of Co content. The debris formed in adhesive wear is left on the worn 
surface and oxidized during the wear tests. The oxides of debris can serve as a solid lubricant in the wear process, and may also contribute to the improvement of the wear resistance of cladding layers.

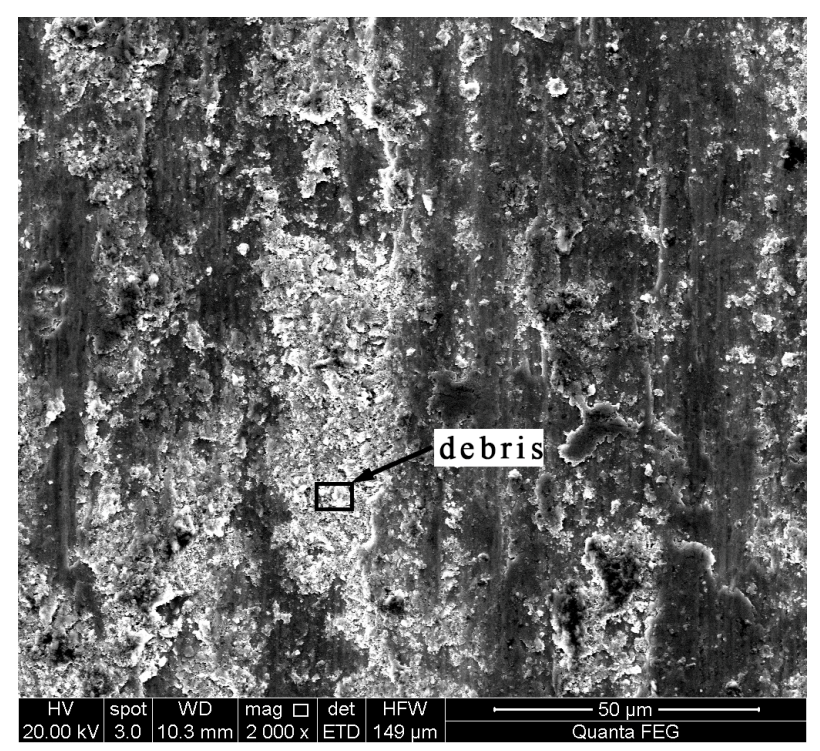

(a)

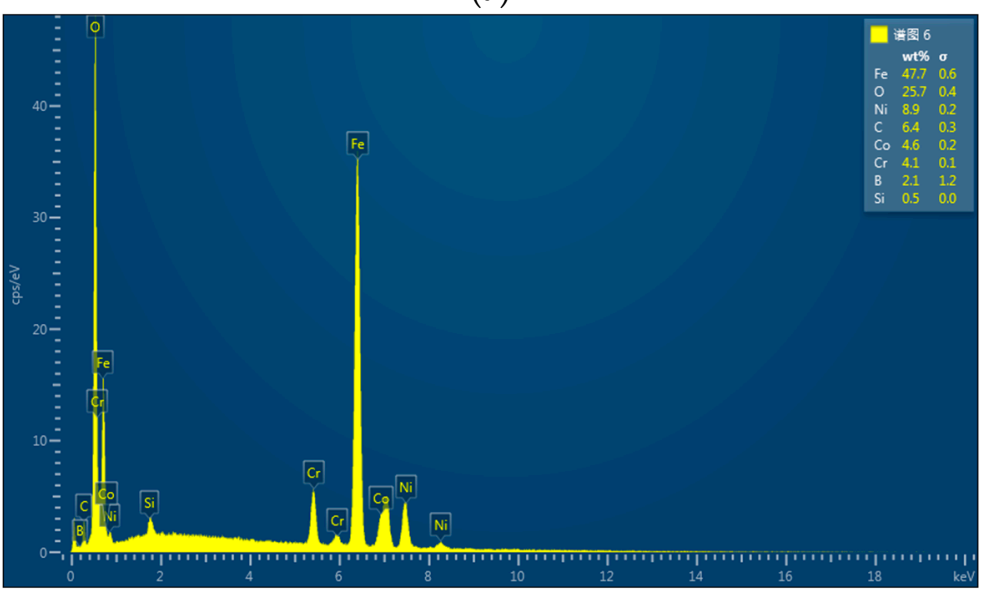

(b)

Figure 8. (a) Worn surface of the NiCo30 cladding layer at a higher magnification; (b) EDS results of debris.

\section{Conclusions}

The Ni-based cladding layers with different Co contents were fabricated on the surface of $42 \mathrm{CrMo}$ steel by laser cladding. Some conclusions can be obtained.

(1) The phases of cladding layers with different $C o$ contents include $\gamma, M_{7}(C, B)_{3}, M_{23}(C, B)_{6}$, and $M_{2} B$, where $\mathrm{M}$ is $\mathrm{Cr}$ and $\mathrm{Fe}$. The amount of $\mathrm{M}_{7}(\mathrm{C}, \mathrm{B})_{3}, \mathrm{M}_{23}(\mathrm{C}, \mathrm{B})_{6}$, and $\mathrm{M}_{2} \mathrm{~B}$ decreases gradually with the increase of the Co content.

(2) Good metallurgical bondings have been achieved between the substrates and the cladding layers. The microstructure of cladding layers are mainly composed of dendrites and eutectic structures. The width of eutectic structures decreases with the increase of the Co content.

(3) The microhardness of the cladding layer decreases, but the wear resistance increases with the increase of Co content. The wear resistance of the NiCo30 coating is about 3.6 times that of the $\mathrm{NiCo00}$ coating. The wear mechanism of the cladding layer is changed from abrasive wear to adhesive wear with the increase of Co content. 
Acknowledgments: The authors appreciate the financial support for this work from National Natural Science Foundation of China (No. 51675303); the Open Foundation of Key Laboratory of E\&M (Zhejiang University of Technology), Ministry of Education \& Zhejiang Province (No. EM2016070103); and the Tribology Science Fund of the State Key Laboratory of Tribology (SKLT2014B09, SKLT2015B09).

Author Contributions: Kaiming Wang performed all experiments and wrote the paper; Baohua Chang and Hanguang $\mathrm{Fu}$ designed the experiments and reviewed the paper; Yinghua Lin performed the experiments; Yongping Lei analyzed the data.

Conflicts of Interest: The authors declare no conflict of interest.

\section{References}

1. Chen, Y.; Guo, Y.; Lu, B.; Xu, M.; Xu, J. Microstructure and properties of the interface area in the laser cladded Ni based coatings on the $1 \mathrm{Cr} 10 \mathrm{Mo1NiWVNbN}$ steel. Metals 2017, 7, 175. [CrossRef]

2. Farahmand, P.; Kovacevic, R. An experimental-numerical investigation of heat distribution and stress field in single- and multi-track laser cladding by a high-power direct diode laser. Opt. Laser Technol. 2014, 63, 154-168. [CrossRef]

3. Corbin, S.F.; Toyserkani, E.; Khajepour, A. Cladding of an Fe-aluminide coating on mild steel using pulsed laser assisted powder deposition. Mater. Sci. Eng. 2003, 354, 48-57. [CrossRef]

4. Wu, F.; Chen, T.; Wang, H.; Liu, D. Effect of Mo on Microstructures and wear properties of in situ synthesized $\mathrm{Ti}(\mathrm{C}, \mathrm{N}) / \mathrm{Ni}$-based composite coatings by laser cladding. Materials 2017, 10, 1047. [CrossRef] [PubMed]

5. Wang, X.; Liu, C.; Xu, L.; Xiao, H.; Zheng, L. Microstructure and mechanical properties of the hot-rolled Mg-Y-Nd-Zr alloy. J. Mater. Res. 2013, 28, 1386-1393. [CrossRef]

6. Xie, M.-X.; Zhang, L.-J.; Zhang, G.-F.; Zhang, J.-X.; Bi, Z.-Y.; Li, P.-C. Microstructure and mechanical properties of CP-Ti/X65 bimetallic sheets fabricated by explosive welding and hot rolling. Mater. Des. 2015, 87, 181-197. [CrossRef]

7. Azevedo, T.F.; Dos Santos, C.R.; De Souza, R.E.A.; Tentardini, E.K.; Griza, S. Failure analysis of the repair procedure of an ore compactor roll. Eng. Fail. Anal. 2013, 31, 195-202. [CrossRef]

8. Ray, A.; Arora, K.S.; Lester, S.; Shome, M. Laser cladding of continuous caster lateral rolls: Microstructure, wear and corrosion characterisation and on-field performance evaluation. J. Mater. Process. Technol. 2014, 214, 1566-1575. [CrossRef]

9. Sampath, S.; Neiser, R.A.; Herman, H.; Kirkland, J.P.; Elam, W.T. A structural investigation of a plasma sprayed Ni-Cr based alloy coating. J. Mater. Res. 1993, 8, 78-86. [CrossRef]

10. Cooke, K.; Oliver, G.; Buchanan, V.; Palmer, N. Optimisation of the electric wire arc-spraying process for improved wear resistance of sugar mill roller shells. Surf. Coat. Technol. 2007, 202, 185-188. [CrossRef]

11. Birger, E.M.; Moskvitin, G.V.; Polyakov, A.N.; Arkhipov, V.E. Industrial laser cladding: Current state and future. Weld. Int. 2011, 25, 234-243. [CrossRef]

12. Lin, Y.; Lei, Y.; Fu, H.; Lin, J. Mechanical properties and toughening mechanism of TiB2/NiTi reinforced titanium matrix composite coating by laser cladding. Mater. Des. 2015, 80, 82-88. [CrossRef]

13. Simunovic, K.; Saric, T.; Simunovic, G. Different approaches to the investigation and testing of the Ni-based self-fluxing alloy coatings-A review. Part 1: General facts, wear and corrosion investigations. Tribol. Trans. 2014, 57, 955-979. [CrossRef]

14. Zhang, H.; Zhang, Z.; Yue, T. The pseudo-eutectic microstructure and enhanced properties in laser-cladded hypereutectic Ti-20\% Si coatings. Metals 2017, 7, 33. [CrossRef]

15. Paatsch, W. Energy turnaround-A challenge for surface technology. Trans. IMF 2016, 94, 228-230. [CrossRef]

16. He, H.; Zhang, T.; Ma, M.; Liu, W. Microstructure and wear resistance of laser cladding particulate reinforced Fe-based composite coating on railway steel. J. Laser Appl. 2017, 29, 22503. [CrossRef]

17. Gao, W.; Zhao, S.; Liu, F.; Wang, Y.; Zhou, C.; Lin, X. Effect of defocus manner on laser cladding of Fe-based alloy powder. Surf. Coat. Technol. 2014, 248, 54-62. [CrossRef]

18. Zhang, L.; Wang, C.; Qian, S.; Yu, Q.; Dong, C. Microstructure and wear resistance of laser-clad (Co, Ni) 61.2B26.2Si7.8Ta4.8 coatings. Metals 2017, 7, 419. [CrossRef]

19. Lewis, S.R.; Lewis, R.; Fletcher, D.I. Assessment of laser cladding as an option for repairing/enhancing rails. Wear 2015, 330-331, 581-591. [CrossRef]

20. Lin, C.-M. Parameter optimization of laser cladding process and resulting microstructure for the repair of tenon on steam turbine blade. Vacuum 2015, 115, 117-123. [CrossRef] 
21. Angelastro, A.; Campanelli, S.L.; Casalino, G.; Ludovico, A.D.; Ferrara, S. A methodology for optimization of the direct laser metal deposition process. Key Eng. Mater. 2011, 473, 75-82. [CrossRef]

22. Xu, J.S.; Zhang, X.C.; Xuan, F.Z.; Wang, Z.D.; Tu, S.T. Microstructure and sliding wear resistance of laser cladded WC/Ni composite coatings with different contents of WC particle. J. Mater. Eng. Perform. 2011, 21, 1904-1911. [CrossRef]

23. Paul, C.P.; Mishra, S.K.; Tiwari, P.; Kukreja, L.M. Solid-particle erosion behaviour of WC/Ni composite clad layers with different contents of WC particles. Opt. Laser Technol. 2013, 50, 155-162. [CrossRef]

24. Chen, Y.; Wang, H.M. Microstructure and wear resistance of a laser clad TiC reinforced nickel aluminides matrix composite coating. Mater. Sci. Eng. 2004, 368, 80-87. [CrossRef]

25. Ma, Q.; Li, Y.; Wang, J.; Liu, K. Investigation on cored-eutectic structure in Ni60/WC composite coatings fabricated by wide-band laser cladding. J. Alloys Compd. 2015, 645, 151-157. [CrossRef]

26. Lei, Y.; Sun, R.; Lei, J.; Tang, Y.; Niu, W. A new theoretical model for high power laser clad TiC/NiCrBSiC composite coatings on Ti6Al4V alloys. Opt. Lasers Eng. 2010, 48, 899-905. [CrossRef]

27. Zhang, G.Y.; Wang, C.L.; Gao, Y. Mechanism of rare earth CeO2 on the Ni-based laser cladding layer of 6063 Al surface. Rare Met. Mater. Eng. 2016, 45, 1002-1006.

28. Ma, Q.; Li, Y.; Wang, J. Effects of Ti addition on microstructure homogenization and wear resistance of wide-band laser clad Ni60/WC composite coatings. Int. J. Refract. Met. Hard Mater. 2017, 64, 225-233.

29. Guo, H.M.; Wang, Q.; Wang, W.J.; Guo, J.; Liu, Q.Y.; Zhu, M.H. Investigation on wear and damage performance of laser cladding Co-based alloy on single wheel or rail material. Wear 2015, 328-329, 329-337. [CrossRef]

30. Clare, A.T.; Oyelola, O.; Abioye, T.E.; Farayibi, P.K. Laser cladding of rail steel with Co-Cr. Surf. Eng. 2013, 29, 731-736. [CrossRef]

31. Bartkowski, D.; Kinal, G. Microstructure and wear resistance of Stellite-6/WC MMC coatings produced by laser cladding using Yb:YAG disk laser. Int. J. Refract. Met. Hard Mater. 2016, 58, 157-164. [CrossRef]

32. Gao, L.; Bian, X.; Tian, Y.; Fu, C. Effect of Co on microstructure and interfacial properties of Fe-based laser cladding. J. Iron Steel Res. Int. 2009, 16, 84-88. [CrossRef]

33. Wang, K.; Chang, B.; Chen, J.; Fu, H.; Lin, Y.; Lei, Y. Effect of molybdenum on the microstructures and properties of stainless steel coatings by laser cladding. Appl. Sci. 2017, 7, 1065. [CrossRef]

34. Wang, K.M.; Fu, H.G.; Li, Y.L.; Lei, Y.P.; Wei, S.Z.; Su, Z.Q. Effect of power on microstructure and properties of laser cladding NiCrBSi composite coating. Trans. IMF 2017, 95, 328-336.

35. Kou, S. Welding Metallurgy; John Wiley \& Sons: Hoboken, NJ, USA, 2003.

36. Gäumann, M.; Bezençon, C.; Canalis, P.; Kurz, W. Single-crystal laser deposition of superalloys: Processing-microstructure maps. Acta Mater. 2001, 49, 1051-1062. [CrossRef]

37. Chang, L.M.; An, M.Z.; Guo, H.F.; Shi, S.Y. Microstructure and properties of Ni-Co/nano-Al2O3 composite coatings by pulse reversal current electrodeposition. Appl. Surf. Sci. 2006, 253, 2132-2137. [CrossRef]

38. Li, Y.M.; Liu, H.J.; Liu, J.; An, B.; Hao, Y. Effect of Co on as-cast structure and properties of K4169 superalloy. Foundry Technol. 2010, 31, 280-283.

39. Chuang, M.-H.; Tsai, M.-H.; Wang, W.-R.; Lin, S.-J.; Yeh, J.-W. Microstructure and wear behavior of AlxCo1.5CrFeNi1.5Tiy high-entropy alloys. Acta Mater. 2011, 59, 6308-6317. [CrossRef]

40. Chakraborty, G.; Kumar, N.; Das, C.R.; Albert, S.K.; Bhaduri, A.K.; Dash, S.; Tyagi, A.K. Study on microstructure and wear properties of different nickel base hardfacing alloys deposited on austenitic stainless steel. Surf. Coat. Technol. 2014, 244, 180-188. [CrossRef]

41. Fernández, M.R.; García, A.; Cuetos, J.M.; González, R.; Noriega, A.; Cadenas, M. Effect of actual WC content on the reciprocating wear of a laser cladding NiCrBSi alloy reinforced with WC. Wear 2015, 324-325, 80-89. [CrossRef]

(C) 2017 by the authors. Licensee MDPI, Basel, Switzerland. This article is an open access article distributed under the terms and conditions of the Creative Commons Attribution (CC BY) license (http:/ / creativecommons.org/licenses/by/4.0/). 